Article

\title{
A Ka-Band Circular Polarized Waveguide Slot Antenna with a Cross Iris
}

\author{
Sung-Joon Yoon $\mathbb{D}$ and Jae-Hoon Choi * $\mathbb{D}$ \\ Department of Electronics and Computer Engineering, Hanyang University, Seoul 133-791, Korea; \\ nais25@hanyang.ac.kr \\ * Correspondence: choijh@hanyang.ac.kr; Tel.: +82-2-2220-0376
}

Received: 30 August 2020; Accepted: 2 October 2020; Published: 7 October 2020

Featured Application: Segment waveguide slot antenna for a satellite communication and radar.

\begin{abstract}
A Ka-band circularly polarized (CP) waveguide slot antenna with a cross iris is proposed. To achieve the CP characteristic (LHCP) in the antenna, a hexagonal shaped cavity is used. The impedance matching is improved by adjusting the sizes of the hexagonal cavity and a rectangular matching cavity. To enhance the axial ratio bandwidth, a cross iris is used with two arms of different lengths. From experimental results, the proposed antenna has a $3 \mathrm{~dB}$ axial ratio bandwidth of $6810 \mathrm{MHz}(31.72 \mathrm{GHz}-38.53 \mathrm{GHz})$. The $-10 \mathrm{~dB}$ reflection coefficient bandwidth of the proposed antenna ranges from $31.51 \mathrm{GHz}$ to $39.21 \mathrm{GHz}(7700 \mathrm{MHz})$.
\end{abstract}

Keywords: waveguide antenna; slot antenna; circular polarization; axial ratio enhancement

\section{Introduction}

Millimeter-wave communication systems support a higher data rate and larger capacity. Millimeter wave frequency has therefore been widely used in various applications such as 5G mobile, radar, satellite, military, and automotive communications [1]. Because mm-wave signals can be easily distorted by atmospheric interference such as fog or dust, waveguide antennas have been considered among the most appropriate for mm-wave applications due to their high power handling, high gain, stable performance and low transmission loss [2,3]. The polarization of antennas is one of the important factors in determining the performance of the communication. For linear polarization antenna, if the polarizations of a transmitter and a receiver do not match each other, communication performance deteriorates. Meanwhile, circular polarization avoids polarization misalignment as the electric field rotates, and it reduces multipath fading with flexibility in orientation the angle between the transmitted receiver [4,5]. Therefore, circular polarized (CP) waveguide antennas in particular are widely used in modern satellite communication systems due to their advantages of enhancing the channel stability and reliability [6,7]. Several techniques have been introduced to realize the waveguide $\mathrm{CP}$ horn and aperture antennas such as using a printed circuit board with four printed hook shaped arms [7], loading two metallic arms with a $45^{\circ}$ inclination angle [8], and inserting a meta-surface polarizer or chiral metamaterial transformer [6,9]. However, there are some limitations in applying them to various applications since these antennas are relatively bulky and heavy. In addition, they are not suitable for array systems because a large space is required for polarizers to be installed [10]. Therefore, such antennas are not appropriate for satellite communication systems requiring a high gain array structure with compact size. To overcome these drawbacks of bulk and mass, various types of circular polarized waveguide slot antennas have been studied [11-17]. Waveguide inclined slot, crossed slot, and v-type slot antennas have been widely used for CP array antennas to generate circularly polarized waves with high gain [13-17]. However, there are few reports on either widening 
the axial ratio bandwidth of the waveguide slot antenna at the millimeter-wave band region or the design of waveguide slot $\mathrm{CP}$ antennas [16,17].

This paper proposes a Ka-band circularly polarized waveguide slot antenna with a cross iris. To achieve a circular polarization characteristic, a hexagonal shaped cavity is used [18]. By mounting a cross iris, the circular polarization performance of the proposed antenna is enhanced. The proposed antenna provides a $-10 \mathrm{~dB}$ reflection coefficient bandwidth covering from $31.51 \mathrm{GHz}$ to $39.21 \mathrm{GHz}$. The $3 \mathrm{~dB}$ axial ratio bandwidth is $6810 \mathrm{MHz}(31.72 \mathrm{GHz}-38.53 \mathrm{GHz})$. The antenna peak gains are $9.08 \mathrm{dBi}$ at $33.5 \mathrm{GHz}$ and $7.33 \mathrm{dBi}$ at $37.6 \mathrm{GHz}$. The boresight gains of $7.87 \mathrm{dBi}$ and $5.76 \mathrm{dBi}$ are achieved at those two frequencies, respectively.

\section{Antenna Design}

Figure 1 shows the structure of the proposed $\mathrm{CP}$ waveguide slot antenna consisting of a rectangular waveguide, an air metal box with hexagonal cavity and matching slot, and a cross iris at the bottom of the rectangular waveguide. The proposed antenna has dimensions of $10.1 \mathrm{~mm} \times 23 \mathrm{~mm} \times 7.06 \mathrm{~mm}$ and is made of a copper with a conductivity of $5.8001 \times 10^{7} \mathrm{~S} / \mathrm{m}$. The detailed parameters of the proposed antenna are shown in Figure 1 and the dimensions are given in Table 1 . The performances of the proposed antenna were simulated using the commercial electromagnetic simulator, High Frequency Structure Simulator (HFSS) [19]. The antenna is fed from the rectangular waveguide to excite the $\mathrm{TE}_{10}$ mode for high power handling capability. The dimensions ( $a=7.11 \mathrm{~mm}$ and $b=3.56 \mathrm{~mm}$ ) of the feeding waveguide are determined by the cutoff frequency $(21.077 \mathrm{GHz})$ using the following equation with dimensions shown in Figure 2 [20]. As shown in Figure 2, the waveguide has its longest dimension along the $\mathrm{x}$-axis $(a)$.

$$
f_{c m n}=\frac{1}{2 \pi \sqrt{\mu_{0} \varepsilon_{0}}} \sqrt{\left(\frac{m \pi}{a}\right)^{2}+\left(\frac{n \pi}{b}\right)^{2}},
$$

When $a>b$, the cutoff frequency of $\mathrm{TE}_{10}(m=1, n=0)$ mode becomes

$$
f_{c 10}=\frac{1}{2 a \sqrt{\mu_{0} \varepsilon_{0}}},
$$

where $\mu_{0}$ and $\varepsilon_{0}$ are the permeability and permittivity of free space, respectively.

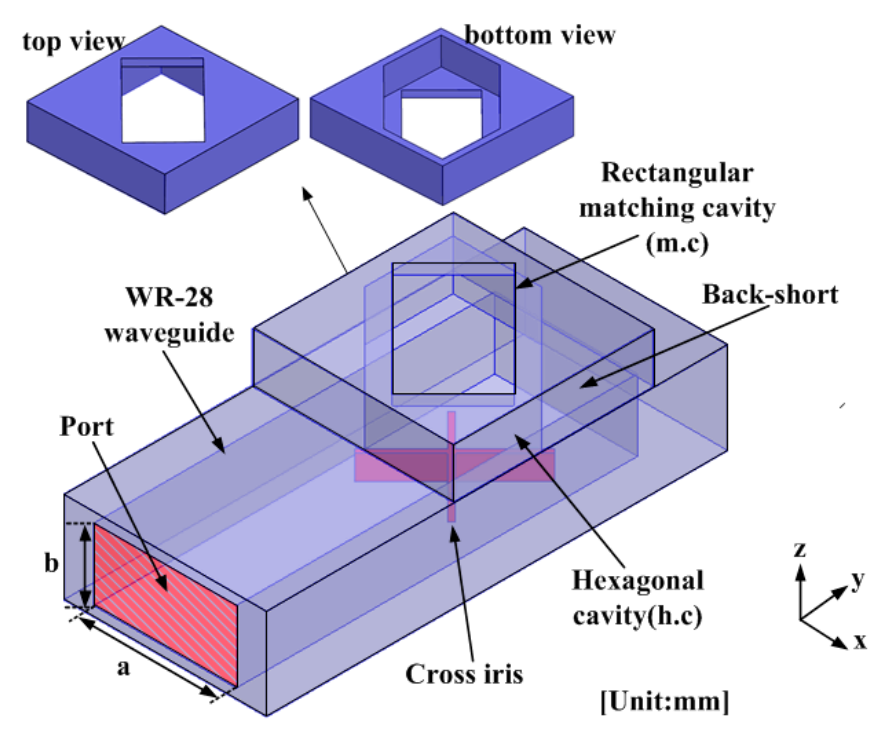

(a)

Figure 1. Cont. 


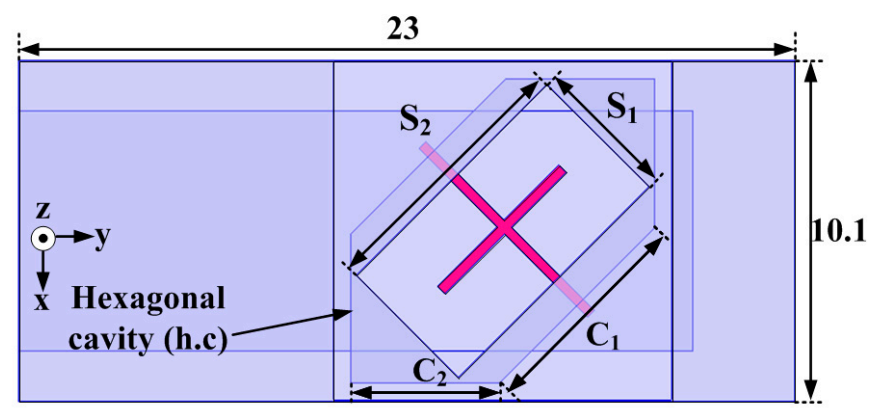

(b)

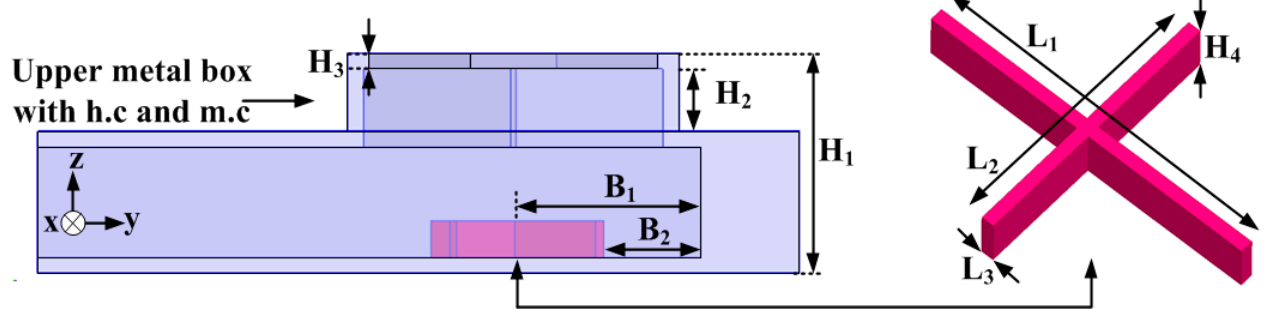

(c)

Figure 1. Geometry of the proposed antenna: (a) 3-D view of the proposed antenna; (b) top view of the proposed antenna; (c) side view of the proposed antenna and cross iris.

Table 1. Dimensions of the proposed antenna.

\begin{tabular}{ccccccc}
\hline Parameters & $C_{1}$ & $C_{2}$ & $S_{1}$ & $S_{2}$ & $L_{1}$ & $L_{2}$ \\
\hline Value (mm) & 6.5 & 4.4 & 4.3 & 8 & 6 & 5 \\
\hline Parameters & $H_{1}$ & $H_{2}$ & $H_{3}$ & $H_{4}$ & $B_{1}$ & $B_{2}$ \\
\hline Value $(\mathrm{mm})$ & 7.06 & 2.5 & 0.5 & 1.2 & 5.9 & 3.28 \\
\hline
\end{tabular}

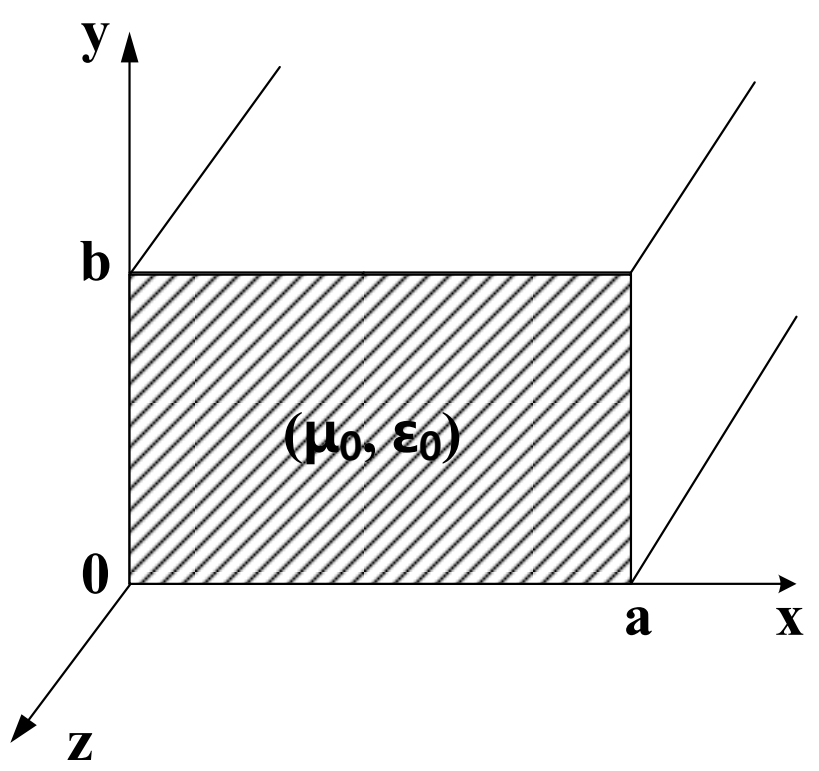

Figure 2. Geometry of the rectangular waveguide. 


\section{Antenna Analysis}

In the proposed antenna design, the hexagonal shaped cavity with a rectangular waveguide shown in Figure 3 is used as an initial model (first reference antenna) to realize the circular polarization. The hexagonal shape is similar to a corner truncated patch antenna, which can be theoretically analyzed using a cavity model with the magnetic walls resonating in TM (Transverse Magnetic) mode [21]. However, this hexagonal cavity resonates TE mode with electrical side walls [22]. The truncated corners make the hexagonal cavity generate E-fields as two orthogonal modes, which are written in this paper as the $E_{1}$ mode and $E_{2}$ mode. As shown in Figure 4, because the truncated part $\left(C_{1}\right)$ acts as additional capacitive loading, the $E_{1}$ mode has slower phase velocity and smaller guided wavelength than does the $E_{2}$ mode. As a result, a CP mode is generated by the addition of a lagging $\left(E_{1}\right)$ mode and leading $\left(E_{2}\right)$ mode.

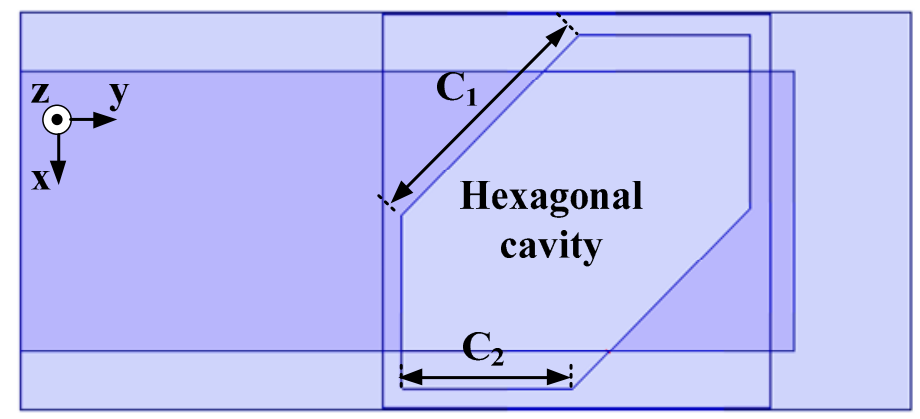

Figure 3. The geometry of the initial model antenna (first reference antenna).

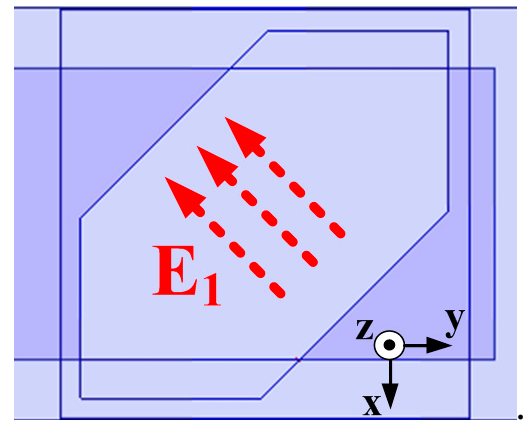

(a)

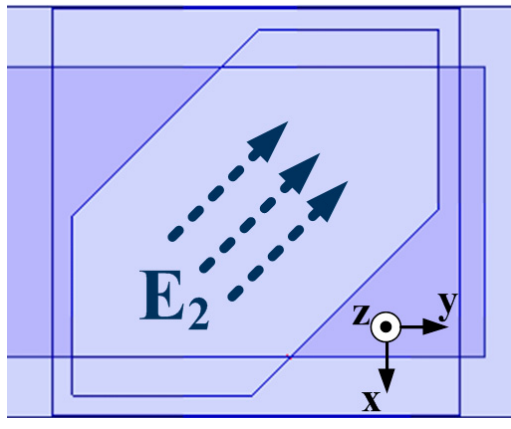

(b)

Figure 4. Definition of the two orthogonal modes: (a) $E_{1}$ mode; (b) $E_{2}$ mode.

In a waveguide antenna, the operating frequency and axial ratio performance are predominantly affected by the dimension and shape of the cavity $[17,22]$. As the dimension of a hexagonal cavity increases, the operation frequency bandwidth is expected to increase. However, the dimension of the hexagonal cavity is limited to the size of a feeding rectangular waveguide. Under such restriction, the lengths of a set of diagonal edges $\left(C_{1}\right.$ and $\left.C_{2}\right)$ of the cavity are optimized to obtain the best performance. Figure 5 shows the simulated reflection coefficient and axial ratio of the first reference antenna with different values of $C_{1}$ and $C_{2}$. As shown in Figure 5, as the dimension of the hexagonal cavity becomes smaller the resonance frequency shifts to the higher side. The circular polarization performance of the first reference antenna is acceptable when $C_{1}=6.5 \mathrm{~mm}$ and $C_{2}=4.4 \mathrm{~mm}$ with the $3 \mathrm{~dB}$ axial ratio bandwidth ranging from $30.37 \mathrm{GHz}$ to $31.2 \mathrm{GHz}$. The first reference antenna has a $-6 \mathrm{~dB}$ reflection coefficient bandwidth of $3250 \mathrm{MHz}$ (from $30.23 \mathrm{GHz}$ to $33.48 \mathrm{GHz}$ ). 


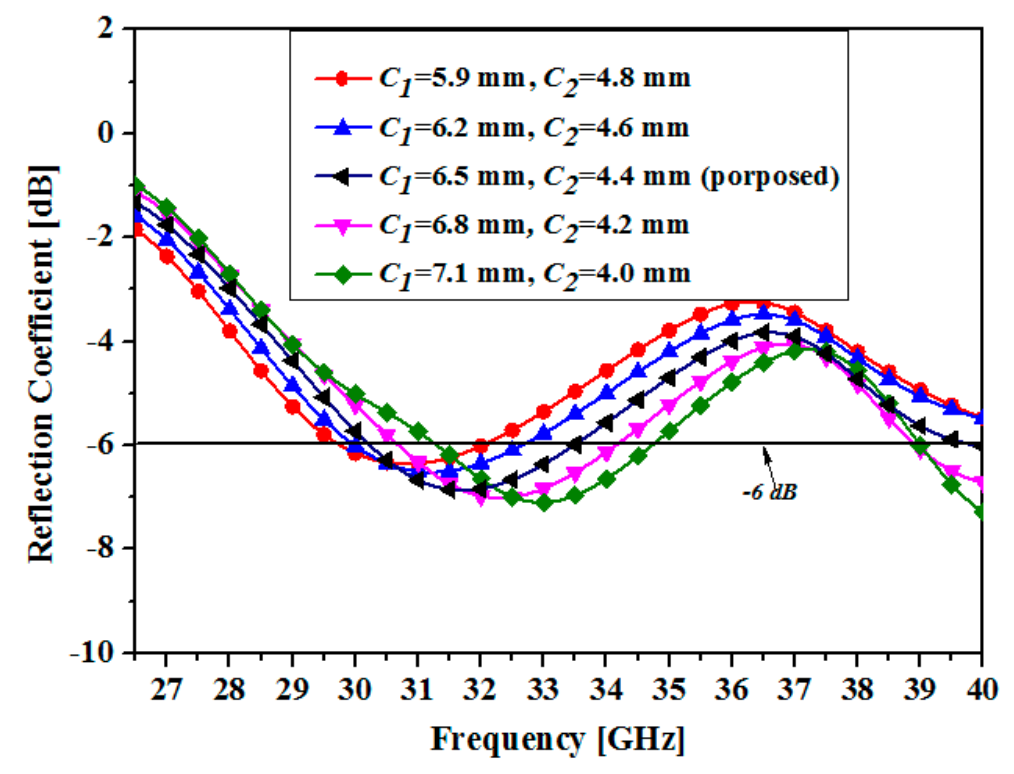

(a)

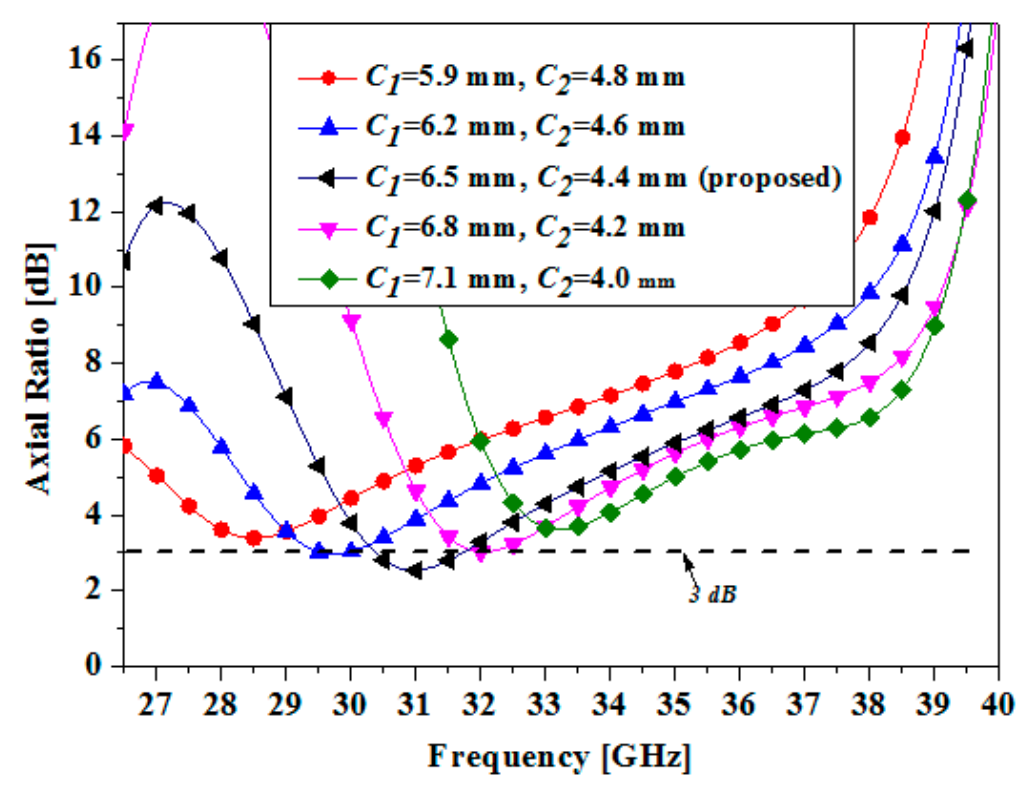

(b)

Figure 5. Simulated (a) reflection coefficient and (b) axial ratio of the first reference antenna for different values of $C_{1}$ and $C_{2}$.

To investigate that the circular polarization characteristic is achieved by the hexagonal cavity, the variation of the electric field distributions of the first reference antenna with different phases at $31 \mathrm{GHz}$ are illustrated in Figure 6. As shown in Figure 6, the electric field rotates clockwise as the phase changes from $0^{\circ}$ to $270^{\circ}$. Therefore, we conclude that the first reference antenna has a left-handed circular polarization (LHCP) characteristic. 


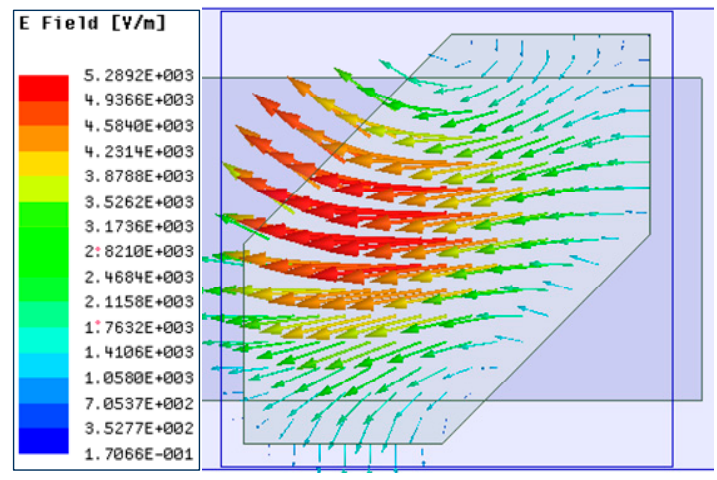

(a)

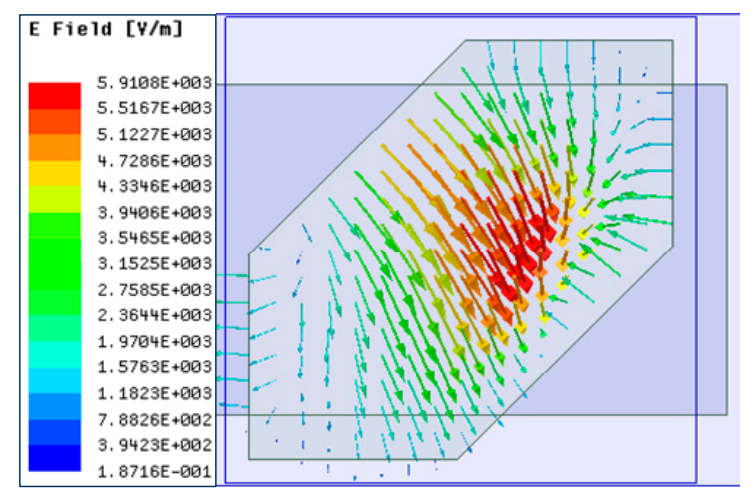

(c)

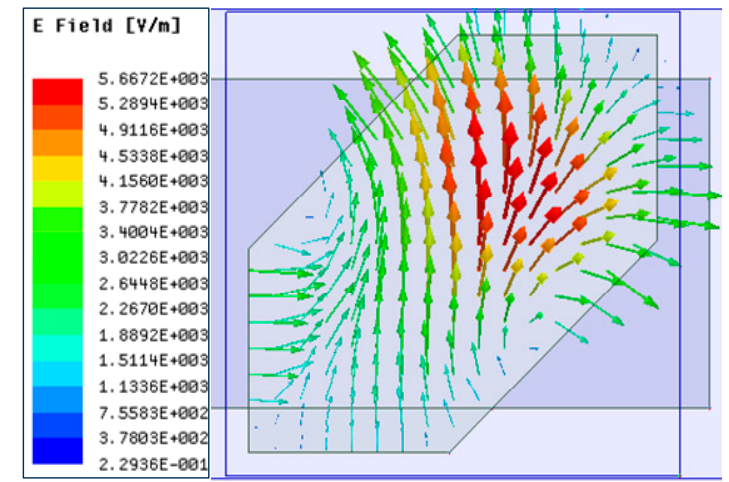

(b)

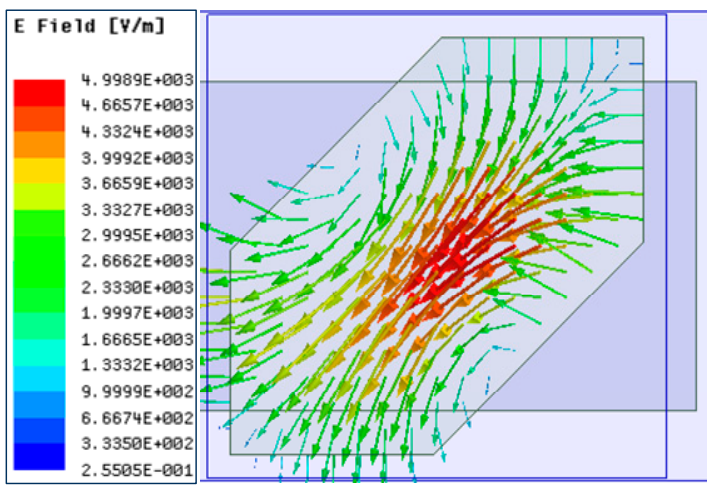

(d)

Figure 6. Simulated electric field distributions of the first reference antenna with different phases at $31 \mathrm{GHz}$ : (a) phase $=0^{\circ} ;(\mathbf{b})$ phase $=90^{\circ} ;(\mathbf{c})$ phase $=180^{\circ} ;(\mathbf{d})$ phase $=270^{\circ}$.

Although the first reference antenna presents a reasonably good $-6 \mathrm{~dB}$ reflection coefficient and $3 \mathrm{~dB}$ axial ratio bandwidth, additional impedance matching is required because satellite applications generally impose a $-10 \mathrm{~dB}$ reflection coefficient criteria for communication efficiency [23]. To improve the impedance matching characteristic, we added a rectangular matching cavity located on the hexagonal cavity (second reference antenna). In the equivalent circuit, the long side $\left(S_{2}\right)$ of the matching cavity acts as a capacitance while the short side $\left(S_{1}\right)$ has an inductive characteristic [24]. Therefore, the impedance matching from the feeding rectangular waveguide to free space is improved through choosing proper values of $S_{1}$ and $S_{2}$ for the height $\left(H_{3}\right)$ of $0.5 \mathrm{~mm}$. The optimized values of $S_{1}$ and $S_{2}$ are $4.3 \mathrm{~mm}$ and $4.8 \mathrm{~mm}$, respectively. As shown in Figure 7, the simulated $-10 \mathrm{~dB}$ impedance bandwidth of the second reference antenna becomes $5690 \mathrm{MHz}(30.81-36.50 \mathrm{GHz})$. Meanwhile, the $3 \mathrm{~dB}$ axial ratio bandwidth obtained is $900 \mathrm{MHz}(31.79-32.69 \mathrm{GHz})$. This result indicates that the resonance frequency is moved to the upper frequency side because the dimension of the aperture changes by the addition of the rectangular matching cavity. A similar observation can be made for the axial ratio characteristic. In the second reference antenna, although the $-10 \mathrm{~dB}$ reflection coefficient bandwidth of $5690 \mathrm{MHz}$ is achieved, most of the bandwidth except for $900 \mathrm{MHz}(31.79 \mathrm{GHz}-32.69 \mathrm{GHz})$ does not satisfy the $3 \mathrm{~dB}$ axial ratio requirement. This challenge often occurs when designing $\mathrm{CP}$ antennas $[17,25]$. 


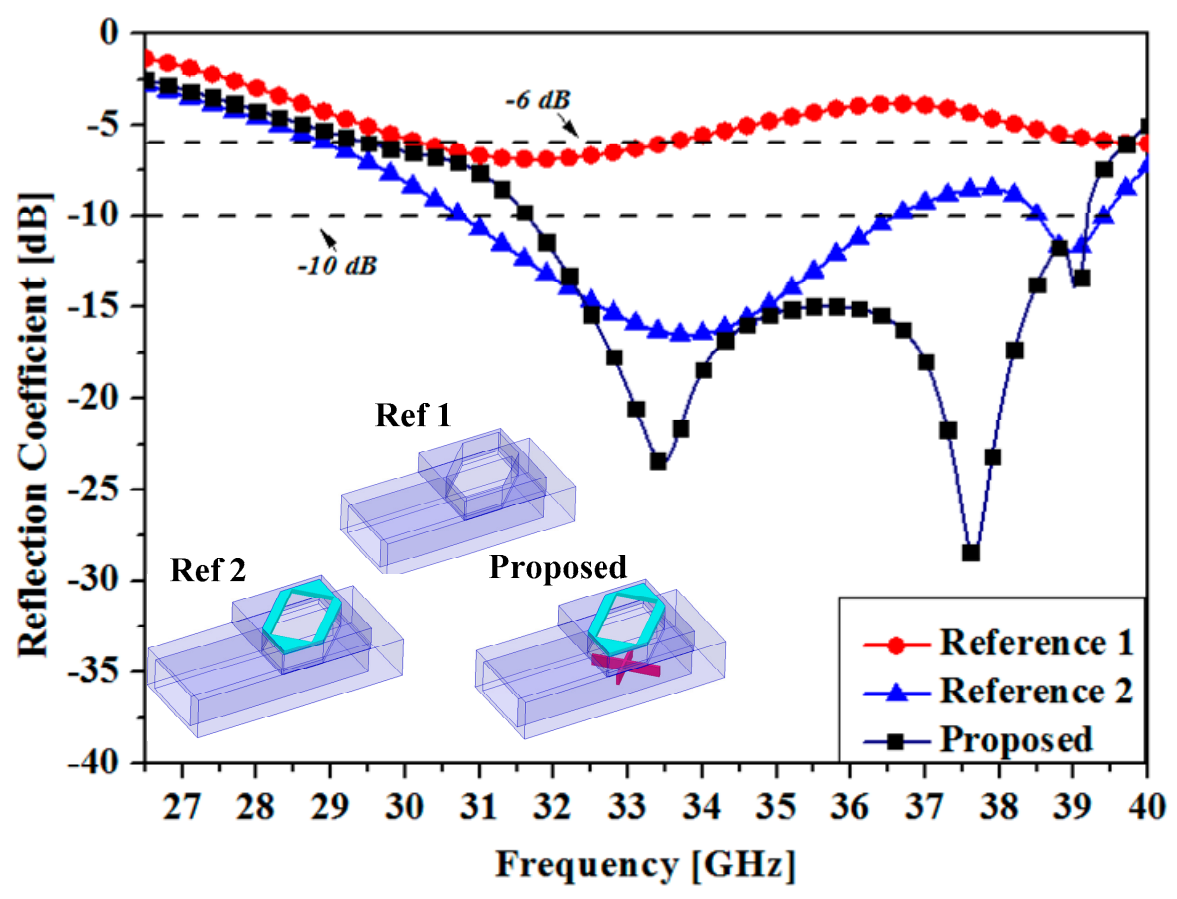

(a)

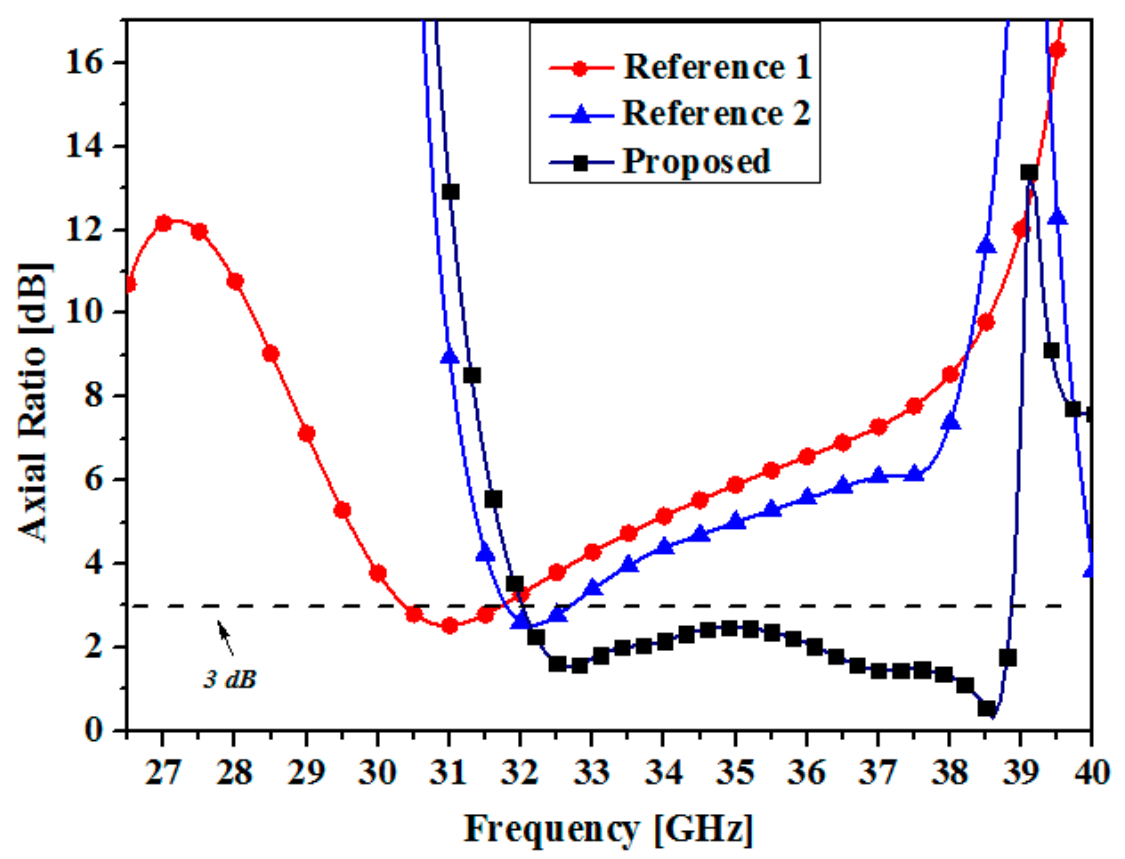

(b)

Figure 7. Simulated (a) reflection coefficient and (b) axial ratio of the first reference antenna, the second reference antenna and proposed antenna.

In the proposed antenna, to resolve this problem, a metallic cross iris is mounted on the bottom of the rectangular feeding waveguide to enhance the axial ratio bandwidth which is an important factor for evaluating the $\mathrm{CP}$ performance. It can be calculated using the following equation [26]. 


$$
A R_{\text {linear scale }}=\frac{\left[r^{2}+1^{2}+\left[r^{4}+1^{4}+2 r^{2} \cos (2 \Delta)\right]^{1 / 2}\right]^{1 / 2}}{\left[r^{2}+1^{2}-\left[r^{4}+1^{4}+2 r^{2} \cos (2 \Delta)\right]^{1 / 2}\right]^{1 / 2}}
$$

where $r$ is the ratio of magnitudes of orthogonal electric fields, and $\Delta$ is the phase difference between the two orthogonal electric fields at the far zone. In general, it can be said that CP operates well when the value of the axial ratio is less than $3 \mathrm{~dB}$. Accordingly, when $r=1$, the phase difference should range from $70^{\circ}$ to $110^{\circ}$ and when $\Delta=90^{\circ}$, the ratio of magnitudes should satisfy the range of $\frac{1}{\sqrt{2}} \leq r \leq \sqrt{2}$.

Figure 8 shows the simulated phase differences between the two orthogonal modes $\left(E_{1}\right.$ and $\left.E_{2}\right)$ of the proposed antenna and the second reference antenna. The phases of the two orthogonal electric fields can be minutely controlled separately because the iris structure consists of two arms with asymmetrical lengths $\left(L_{1}\right.$ and $\left.L_{2}\right)$. By adjusting the lengths of the cross iris, the improved $90^{\circ}$ phase difference range $\left(70^{\circ}\right.$ to $\left.110^{\circ}\right)$ is achieved $(31.70 \mathrm{GHz}-39.25 \mathrm{GHz})$. However, the $3 \mathrm{~dB}$ axial ratio bandwidth is not the same as the $90^{\circ}$ phase difference range because the ratio of the magnitude of the two orthogonal electric fields should be considered.

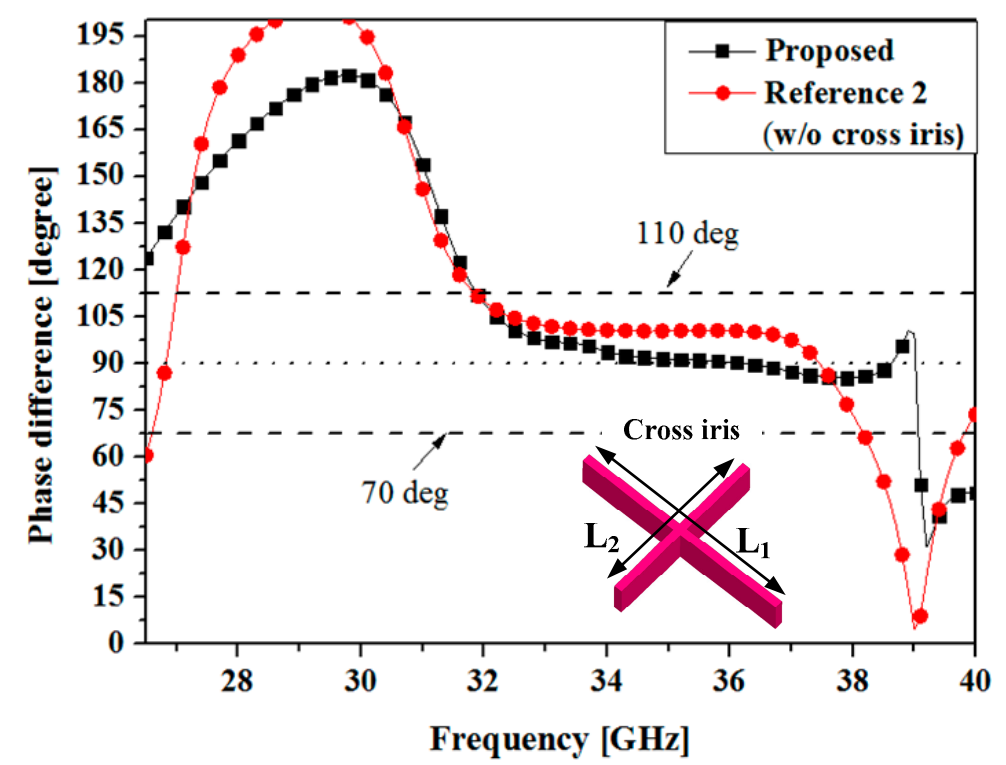

Figure 8. Simulated phase difference between two orthogonal electric fields of the proposed antenna and the second reference antenna.

To analyze how the cross iris affects the magnitude of the two electric fields, simulated amplitudes of the two orthogonal modes of the proposed antenna and the second reference antenna are presented in Figure 9. In the second reference antenna, the two points where the mode lines cross are located at $30.04 \mathrm{GHz}$ and $31.80 \mathrm{GHz}$. At these two points, the magnitudes of the two modes are equal. However, as shown in Figure 8, because the $90^{\circ}$ phase difference range of the second reference antenna is from $31.7 \mathrm{GHz}$, it cannot be said that $\mathrm{CP}$ is generated at less than $31.7 \mathrm{GHz}$. Moreover, the difference in amplitude between the two modes from the second point $(31.8 \mathrm{GHz})$ is increasing, which indicates deteriorated $\mathrm{CP}$ performance. For the proposed antenna, the magnitudes of the two orthogonal modes are equal at three points $(30.75 \mathrm{GHz}, 32.32 \mathrm{GHz}$, and $38.44 \mathrm{GHz})$. In addition, the amplitudes of the two modes become close to each other over the whole frequency range from $(32.32 \mathrm{GHz}$ to $38.44 \mathrm{GHz})$. It can be said that the proposed antenna has a good equal magnitude characteristic. 


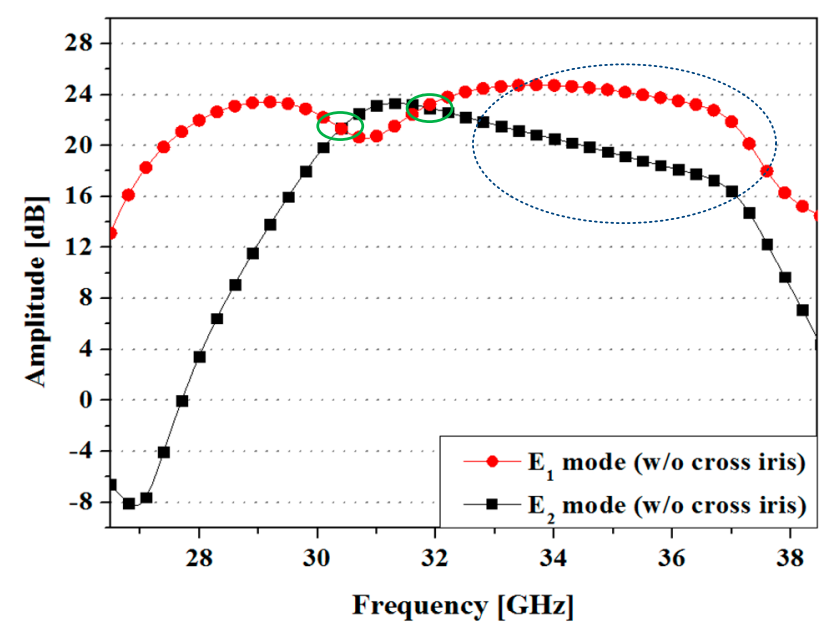

(a)

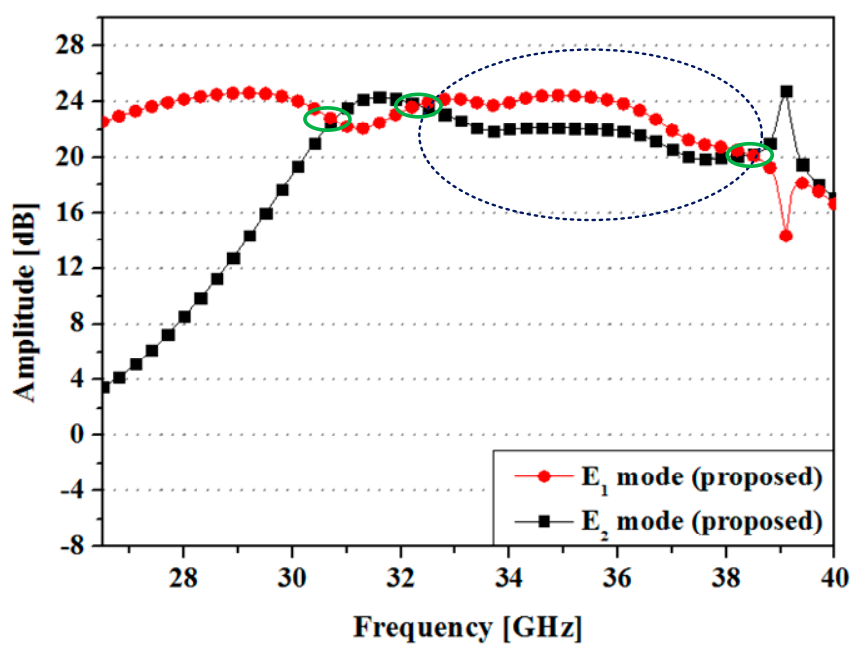

(b)

Figure 9. Simulated amplitudes of $E_{1}$ and $E_{2}$ modes of (a) the second reference antenna and (b) the proposed antenna.

Figure 10 depicts the simulated amplitudes of $E_{1}$ and $E_{2}$ modes for various values of two different lengths $\left(L_{1}\right.$ and $\left.L_{2}\right)$ of the cross iris. The long side of $\left(L_{1}\right)$ of the cross iris has a more dominant effect on the amplitude of $E_{2}$ mode than on $E_{1}$ mode. The $E_{1}$ mode changes more with the variation in the length of short side $\left(L_{2}\right)$. Therefore, we can conclude that the amplitude of $E_{2}$ mode increases as $L_{1}$ increases and that the amplitude of $E_{1}$ mode increases as $L_{2}$ increases. When $L_{1}=6 \mathrm{~mm}$ and $L_{2}=5 \mathrm{~mm}$, a good magnitude match occurs between the two modes with a wide $90^{\circ}$ phase difference range, leading to the wide axial ratio bandwidth. Additionally, because the cross iris has a height of $1.2 \mathrm{~mm}$, it acts as a step between the rectangular waveguide and the radiation slot resulting in gradual change in the impedance so that the matching condition is improved [27].

Figure 11 shows the simulated reflection coefficients when the height of the cross iris $\left(H_{4}\right)$ varies from $0.8 \mathrm{~mm}$ to $1.2 \mathrm{~mm}$. When $H_{4}$ equals $1.2 \mathrm{~mm}$, an enhanced impedance bandwidth is obtained. As a result, as shown in Figure 7, the proposed antenna achieves the simulated $3 \mathrm{~dB}$ axial ratio bandwidth of $6479 \mathrm{MHz}$ (31.97 GHz to $38.45 \mathrm{GHz}$ ) and a $-10 \mathrm{~dB}$ reflection coefficient bandwidth of $6840 \mathrm{MHz}$ (31.74 GHz to $38.58 \mathrm{GHz})$. 

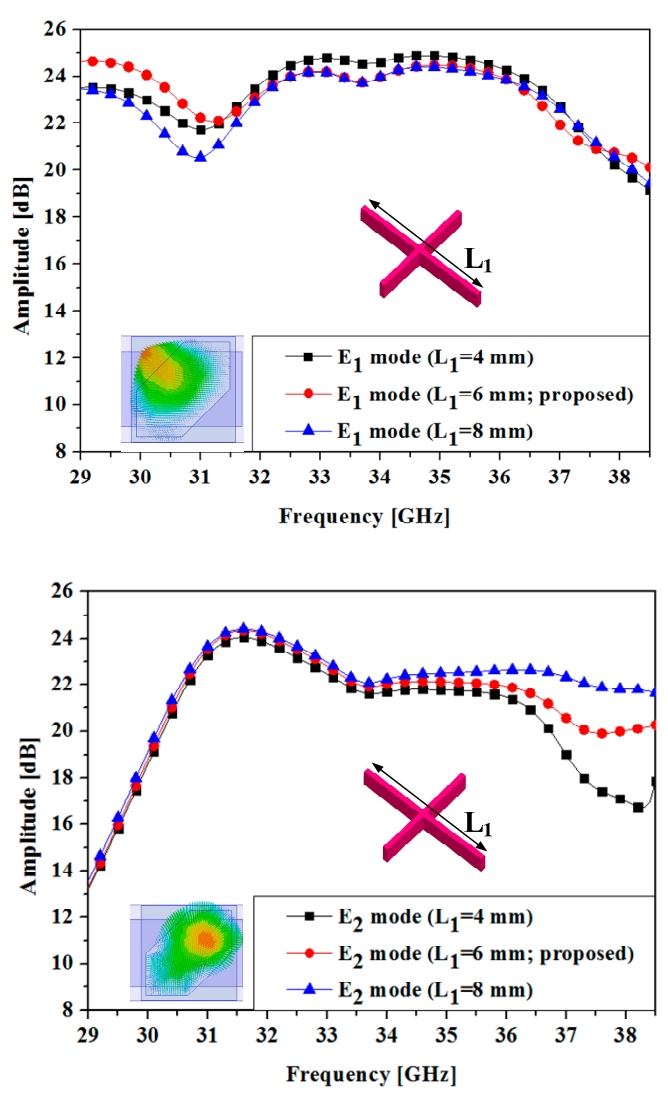

(a)
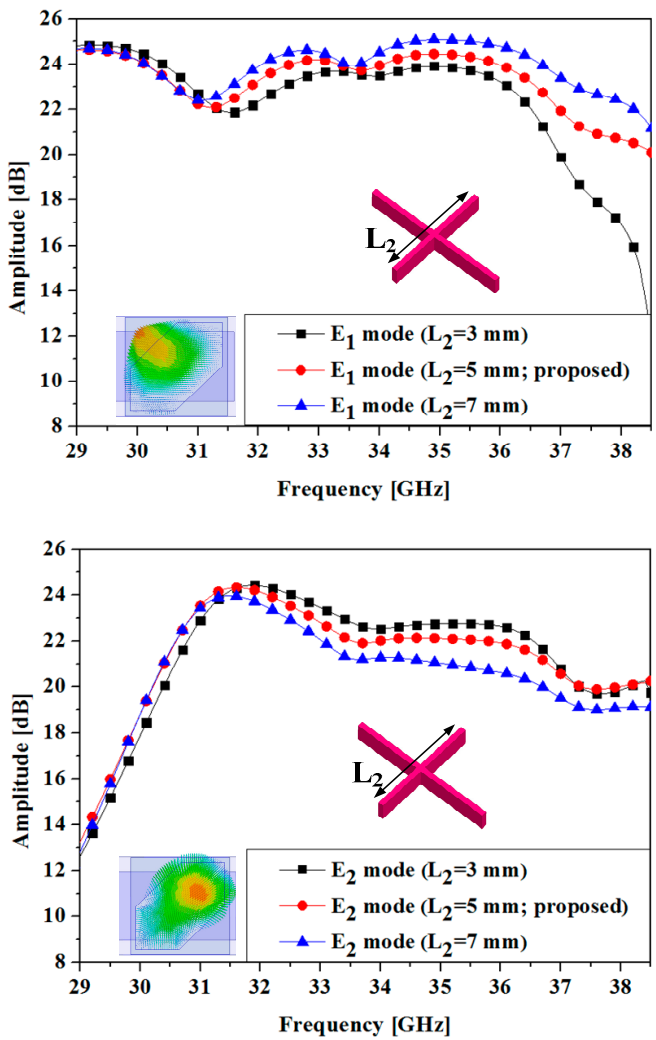

(b)

Figure 10. Simulated amplitudes of $E_{1}$ and $E_{2}$ modes for various values of (a) $L_{1}$ ( $L_{2}$ is fixed at $5 \mathrm{~mm}$ ) and (b) $L_{2}\left(L_{1}\right.$ is fixed at $\left.6 \mathrm{~mm}\right)$. 


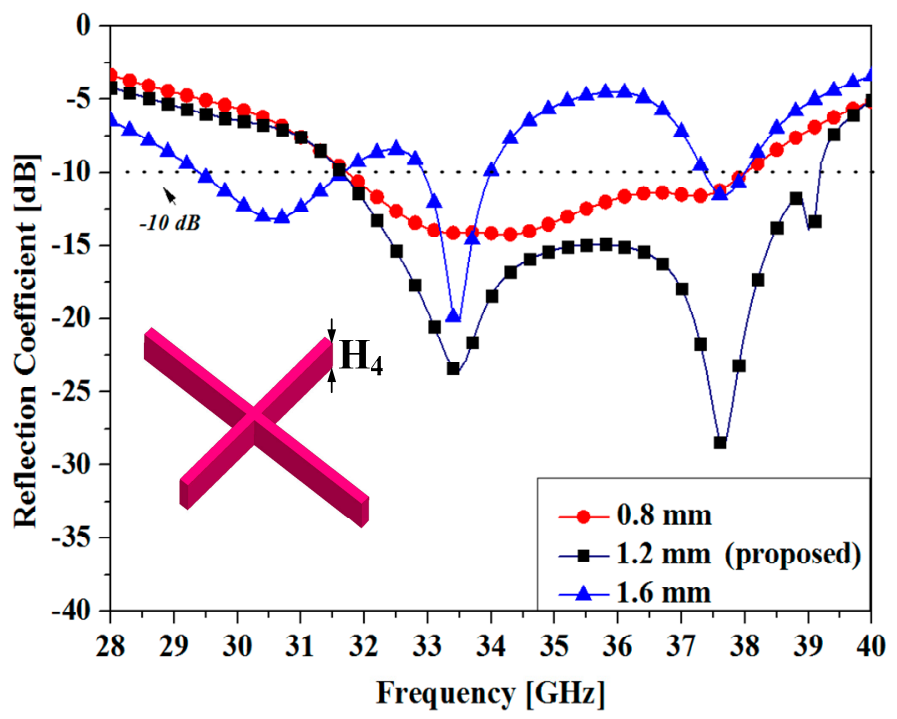

Figure 11. Simulated reflection coefficients for different height $\left(H_{4}\right)$ values of the cross iris.

\section{Experimental Results}

Photographs of the fabricated antenna are shown in Figure 12. The manufactured antenna is assembled in two parts: an upper cavity and a rectangular waveguide with a cross iris. To minimize manufacturing errors, the electroforming process was used. For measuring the reflection coefficient and the radiation pattern with the axial ratio, an Agilent N5247A vector network analyzer with Agilent R11644A calibration kit with a WR-28 coaxial to waveguide adapter were used. They were measured inside the millimeter-wave anechoic chamber equipped with MTG operating software. Figure 13 shows the simulated and measured reflection coefficients and axial ratio of the proposed antenna. The measured $-10 \mathrm{~dB}$ reflection coefficient bandwidth is $7700 \mathrm{MHz}(31.51 \mathrm{GHz}-39.21 \mathrm{GHz})$ and the fractional bandwidth is about $21.7 \%$. The measured $3 \mathrm{~dB}$ axial ratio bandwidth is $6810 \mathrm{MHz}$ $(31.72 \mathrm{GHz}-38.53 \mathrm{GHz})$ and the fractional bandwidth is about $19.38 \%$. There are slight discrepancies between the simulation and measurement results. The discrepancies are due to the differences in the cross iris dimensions of simulation and those of the manufactured antenna.

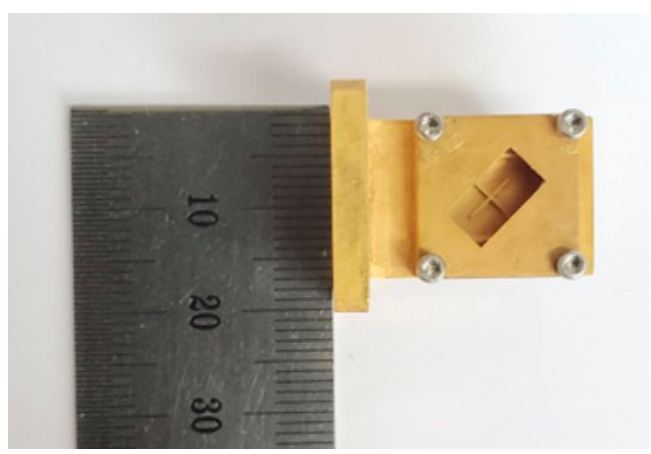

(a)

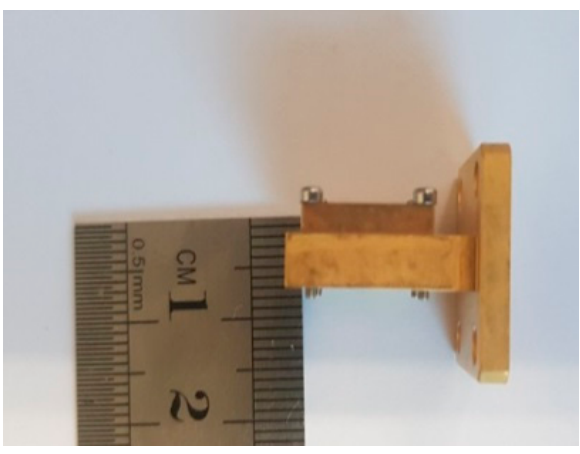

(b)

Figure 12. Cont. 


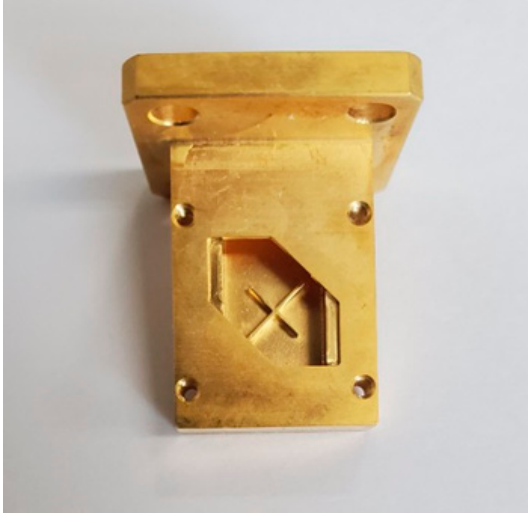

(c)

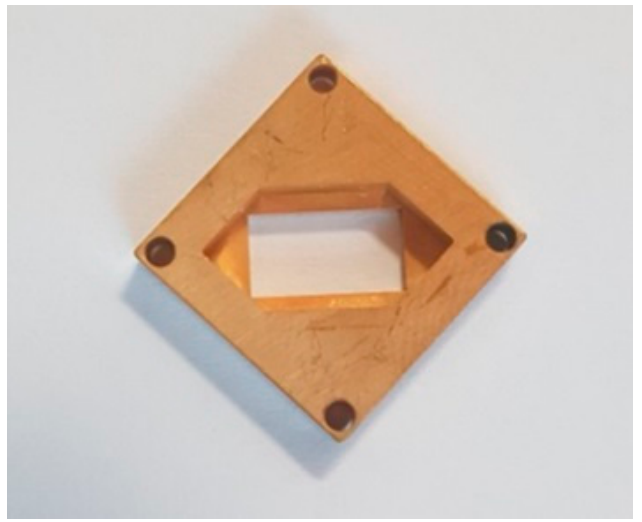

(d)

Figure 12. Photographs of the fabricated antenna: (a) top view; (b) side view; (c) top view of the bottom waveguide; (d) bottom view of the upper cavity.

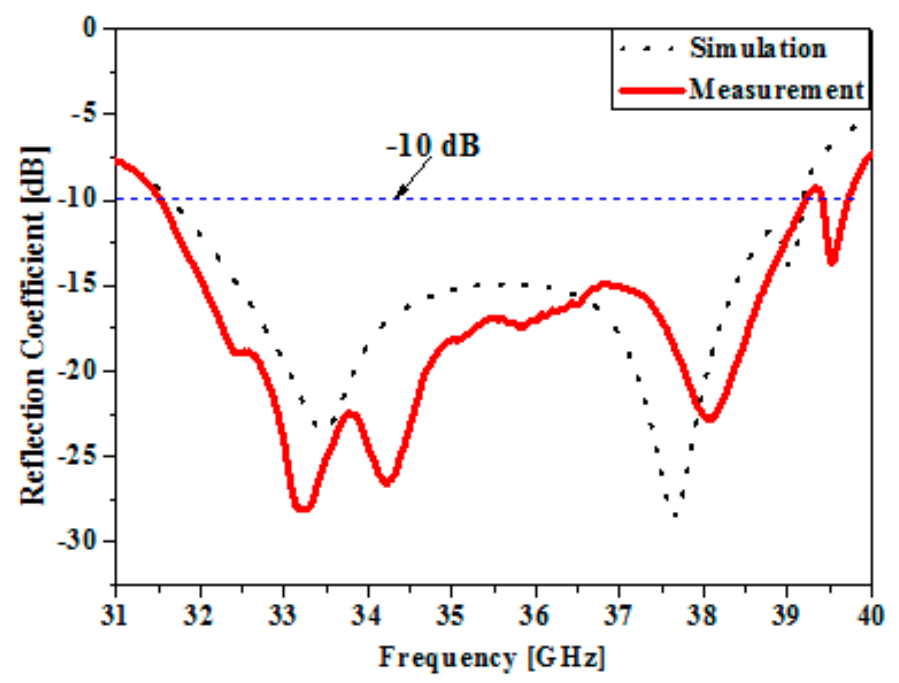

(a)

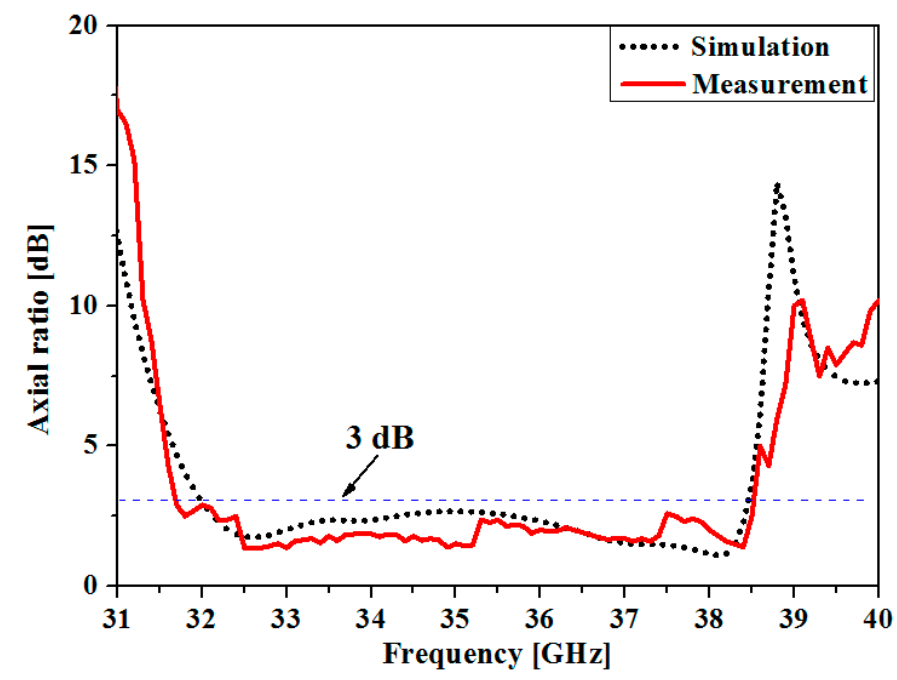

(b)

Figure 13. Simulated and measured (a) reflection coefficients and (b) axial ratio of the proposed antenna. 
Figure 14 shows the simulated and measured radiation patterns of the proposed antenna in the xz-plane $\left(\varnothing=0^{\circ}\right)$ and yz-plane $\left(\varnothing=90^{\circ}\right)$ at $33.5 \mathrm{GHz}$ and $37.6 \mathrm{GHz}$. The simulated and measured radiation patterns agree well in both the $\mathrm{xz}$ and yz planes. It can be observed that the antenna has directional patterns with the inclined maximum gains due to the effect of a hexagonal shaped cavity. The simulated bore-sight gains are $8.27 \mathrm{dBi}$ and $6.13 \mathrm{dBi}$, and those measured are $7.87 \mathrm{dBi}$ and $5.76 \mathrm{dBi}$ at $33.5 \mathrm{GHz}$ and $37.6 \mathrm{GHz}$, respectively. At $33.5 \mathrm{GHz}$, the maximum gain of $9.08 \mathrm{dBi}$ is achieved at $18^{\circ}$ in the xz-plane. At $37.6 \mathrm{GHz}$, the peak gain of $7.33 \mathrm{dBi}$ is obtained at $24^{\circ}$ in the xz-plane.

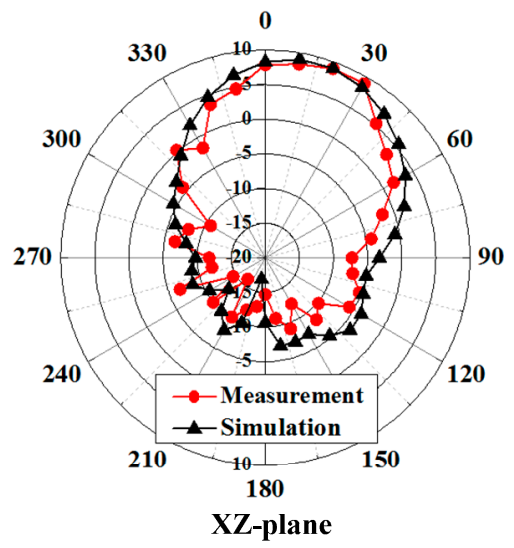

(a)

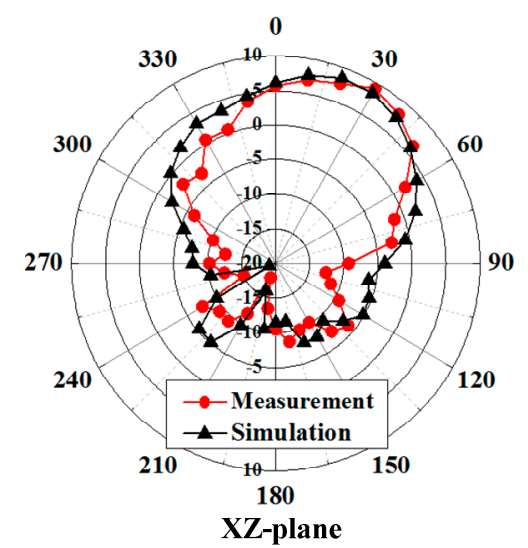

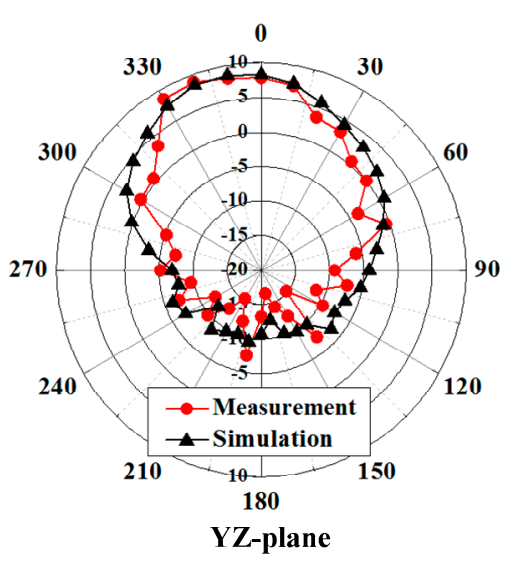

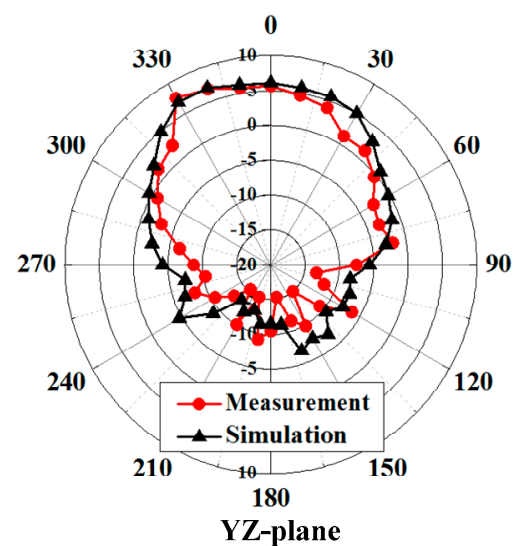

(b)

Figure 14. Simulated and measured radiation pattern of the proposed antenna at (a) $33.5 \mathrm{GHz}$, and (b) $37.6 \mathrm{GHz}$.

Table 2 compares the dimensions, 3- $\mathrm{dB}$ axial ratio bandwidth, and $-10 \mathrm{~dB}$ reflection coefficient bandwidth values from the literature with those of the proposed antenna. The fractional 3-dB axial ratio bandwidth of the proposed antenna is much wider than the others with a broad overlapping bandwidth (88\%) over which both the $3 \mathrm{~dB}$ axial ratio and $-10 \mathrm{~dB}$ reflection coefficient requirements are satisfied. Even though some antennas [11,12] have a shorter length, their overlapping bandwidths $(40.5 \%$ and $50 \%)$ are much smaller than that of the proposed antenna. The antenna in [17] has a very narrow $3 \mathrm{~dB}$ axial ratio and $-10 \mathrm{~dB}$ reflection coefficient bandwidth even with the size comparable to the proposed antenna. Therefore, the proposed antenna has several advantages over other waveguide $\mathrm{CP}$ antennas such as a good $\mathrm{CP}$ characteristic with a wide operating frequency and a low profile. 
Table 2. Performance comparison between literature antennas and the proposed antenna.

\begin{tabular}{cccc}
\hline Ref. & $\begin{array}{c}\text { Dimensions }\left(\lambda_{\text {min }}\right) \\
\text { (Length of Long Side } \times \text { Height) }\end{array}$ & $\begin{array}{c}\text { 3-dB AR Band (GHz) } \\
\text { (Fractional Bandwidth) }\end{array}$ & $\begin{array}{c}-\mathbf{1 0 ~ d B ~ R e f l e c t i o n ~} \\
\text { Coefficient Band(GHz) } \\
\text { (Fractional Bandwidth) }\end{array}$ \\
\hline$[7]$ & $1.54 \times 0.81$ & $12.2-12.8(4.8 \%)$ & $12.15-12.8(5.2 \%)$ \\
{$[11]$} & $0.4 \times 0.44$ & $18.5-22.2(17 \%)$ & $19.7-21.2(7 \%)$ \\
{$[12]$} & $0.14 \times 0.31$ & $33.5-37.5(11.3 \%)$ & $32-40(22.2 \%)$ \\
{$[16]$} & $0.78 \times 0.92$ & $28.8-32.85(13.5 \%)$ & $26.85-32.85(20 \%)$ \\
{$[17]$} & $0.92 \times 0.25$ & $29.69-30.06(1.2 \%)$ & $29-31(6 \%)$ \\
Proposed & $0.95 \times 0.26$ & $31.72-38.53(19.3 \%)$ & $31.51-39.21(21.7 \%)$ \\
\hline
\end{tabular}

\section{Conclusions}

In this paper, a Ka-band circularly polarized waveguide slot antenna with a cross iris is proposed. By using a hexagonal shape cavity, the proposed antenna achieves a circular polarization characteristic (LHCP) by generating two orthogonal modes. Improved impedance matching is realized by applying a rectangular matching slot, which acts as capacitance and inductance in the equivalent circuit. In addition, widening the axial ratio bandwidth is introduced by using a cross iris. Through adjusting the two different lengths of the cross iris, equal amplitude and $90^{\circ}$ phase difference between two orthogonal electric field modes are realized over the wide $-10 \mathrm{~dB}$ reflection coefficient bandwidth. From the experimental results, a $21.7 \%(31.51 \mathrm{GHz}-39.21 \mathrm{GHz})$ fractional impedance bandwidth for $-10 \mathrm{~dB}$ reflection coefficient is obtained. The measured $3 \mathrm{~dB}$ axial ratio bandwidth is $6810 \mathrm{MHz}$ $(31.72 \mathrm{GHz}-38.53 \mathrm{GHz}$ ) and the fractional bandwidth is about $19.38 \%$. Because the overlap between the $3 \mathrm{~dB}$ axial ratio bandwidth and $-10 \mathrm{~dB}$ reflection coefficient bandwidth is greater than $88 \%$, we can conclude that the proposed antenna is well suited for the design goal. Along with the wide operating frequency bandwidth, the proposed antenna has a high gain with a directional pattern showing relatively good agreement between the simulated and measured results. Furthermore, since the proposed antenna is made of all metal and is compact in size, it can be a good candidate for tough operating environments such as radar, spacecraft, and satellite communication.

Author Contributions: The presented work was carried out in collaboration between all the authors. S.-J.Y. wrote the paper. J.-H.C. supervised the research. All authors have read and agreed to the published version of the manuscript.

Funding: This work was supported by the Human Resources Development program (No. 20194010201860) of the Korea Institute of Energy Technology Evaluation and Planning (KETEP) grant funded by the Korea government Ministry of Trade, Industry and Energy.

Conflicts of Interest: The authors declare no conflict of interest.

\section{References}

1. Rappaport, T.S.; Xing, Y.; MacCartney, G.R.; Molisch, A.F.; Mellios, E.; Zhang, J. Overview of millimeter wave communications for fifth-generation $(5 \mathrm{~g})$ wireless networks-with a focus on propagation models. IEEE Trans. Antennas Propag. 2017, 65, 6213-6230. [CrossRef]

2. Leung, K.W.; So, K. Rectangular waveguide excitation of dielectric resonator antenna. IEEE Trans. Antennas Propag. 2003, 51, 2477-2481. [CrossRef]

3. Montisci, G.; Musa, M.; Mazzarella, G. Waveguide slot antennas for circularly polarized radiated field. IEEE Trans. Antennas Propag. 2004, 52, 619-623. [CrossRef]

4. Fukusako, T. Broadband characterization of circularly polarized waveguide antennas using l-shaped probe. J. Electromagn. Eng. Sci. 2017, 17,1-8. [CrossRef]

5. Wang, M.; Hu, L.; Chen, J.; Qi, S.-S.; Wu, W. Wideband circularly polarized square slot array fed by slotted waveguide for satellite communication. Prog. Electromagn. Res. Lett. 2016, 61, 111-118. [CrossRef]

6. Ma, X.; Huang, C.; Pan, W.; Zhao, B.; Cui, J.; Luo, X. A dual circularly polarized horn antenna in ku-band based on chiral metamaterial. IEEE Trans. Antennas Propag. 2014, 62, 2307-2311. [CrossRef] 
7. Qi, S.-S.; Wu, W.; Fang, D.-G. Singly-fed circularly polarized circular aperture antenna with conical beam. IEEE Trans. Antennas Propag. 2013, 61, 3345-3349. [CrossRef]

8. Zhao, Y.; Wei, K.; Zhang, Z.; Feng, Z. A waveguide antenna with bidirectional circular polarizations of the same sense. IEEE Antennas Wirel. Propag. Lett. 2013, 12, 559-562. [CrossRef]

9. Lin, C.; Ge, Y.; Bird, T.S.; Liu, K. Circularly polarized horns based on standard horns and a metasurface polarizer. IEEE Antennas Wirel. Propag. Lett. 2018, 17, 480-484. [CrossRef]

10. Zhang, T.-L.; Yan, Z.-H. A ka dual-band circular waveguide polarizer. In Proceedings of the 20067 th International Symposium on Antennas, Propagation \& EM Theory, Guilin, China, 26 October 2006; Institute of Electrical and Electronics Engineers (IEEE): Piscataway, NJ, USA, 2006; pp. 1-4.

11. Ferrando-Rocher, M.; Herranz-Herruzo, J.I.; Valero-Nogueira, A.; Rodrigo, V.M.; Rodrigo-Penarrocha, V. Circularly polarized slotted waveguide array with improved axial ratio performance. IEEE Trans. Antennas Propag. 2016, 64, 4144-4148. [CrossRef]

12. Li, T.; Fan, F. Design of ka-band $2 \times 2$ circular polarization slot antenna array fed by ridge gap waveguide. In Proceedings of the 2017 Sixth Asia-Pacific Conference on Antennas and Propagation (APCAP), Xi'an, China, 6-19 October 2017; pp. 1-3.

13. Hirano, T.; Hirokawa, J.; Ando, M. Waveguide matching crossed-slot. IEEE Proc.-Microw. Antennas Propag. 2003, 150, 143-146. [CrossRef]

14. Salari, M.; Movahhedi, M. A new configuration for circularly polarized waveguide slot antenna. In Proceedings of the Asia-Pacific Microwave Conference 2011, Melbourne, Australia, 5-8 December 2011; pp. 606-609.

15. Montisci, G. Design of circularly polarized waveguide slot linear arrays. IEEE Trans. Antennas Propag. 2006, 54, 3025-3029. [CrossRef]

16. Kai, Z.; Jianying, L.; Yi, Y.; Rui, X. A novel design of circularly polarized waveguide antenna. In Proceedings of the 2014 3rd Asia-Pacific Conference on Antennas and Propagation, Harbin, China, 26-29 July 2014; Institute of Electrical and Electronics Engineers (IEEE): Piscataway, NJ, USA, 2014; pp. 130-133.

17. Wu, X.; Yang, F.; Xu, F.; Zhou, J. Circularly polarized waveguide antenna with dual pairs of radiation slots at ka-band. IEEE Antennas Wirel. Propag. Lett. 2017, 16, 2947-2950. [CrossRef]

18. Bhardwaj, S.; Volakis, J.L. Circularly-polarized horn antennas for terahertz communication using differential-mode dispersion in hexagonal waveguides. In Proceedings of the 2017 IEEE International Symposium on Antennas and Propagation \& USNC/URSI National Radio Science Meeting, California, CA, USA, 9-14 July 2017; pp. 2571-2572. [CrossRef]

19. Ansys High Frequency Structure Simulator (HFSS); Ansys Corporation: Ansys Drive Canonsburg, PA, USA, 2018; ver.17.2.

20. Pozar, D.M. Microwave Engineering, 4th ed.; John Wily \& Sons, Inc.: New York, NY, USA, 2012; pp. $110-113$.

21. Lo, Y.; Solomon, D.; Richards, W. Theory and experiment on microstrip antennas. IRE Trans. Antennas Propag. 1979, 27, 137-145. [CrossRef]

22. Gan, T.H.; Tan, E.L. Design of broadband circular polarization truncated horn antenna with single feed. Prog. Electromagn. Res. C 2011, 24, 197-206. [CrossRef]

23. Yuan, H.; Qu, S.; Zhang, J.; Zhou, H.; Wang, J.; Ma, H.; Xu, Z. Dual-band dual-polarized spiral antenna for chinese compass navigation satellite system. Prog. Electromagn. Res. Lett. 2014, 46, 25-30. [CrossRef]

24. Boyd, C.R. Impedance matching of open-ended waveguide radiating elements. In Proceedings of the SBMO International Microwave Symposium, Rio de Janeiro, Brazil, 27-30 July 1987.

25. Park, D.; Qu, L.; Kim, H. Compact circularly polarized antenna utilizing the radiation of the ground plane based on the theory of characteristic modes. IET Microw. Antennas Propag. 2019, 13, 1509-1514. [CrossRef]

26. Balanis, C.A. Antenna theory analysis and design, 3rd ed.; Wiley Interscience: Hoboken, NJ, USA, 2005; pp. 70-79.

27. Chu, Q.-X.; Kang, Z.-Y.; Wu, Q.-S.; Mo, D.-Y. An in-phase output $k a$-band traveling-wave power divider/combiner using double ridge-waveguide couplers. IEEE Trans. Microw. Theory Tech. 2013, 61, 3247-3253. [CrossRef]

(C) 2020 by the authors. Licensee MDPI, Basel, Switzerland. This article is an open access article distributed under the terms and conditions of the Creative Commons Attribution (CC BY) license (http://creativecommons.org/licenses/by/4.0/). 